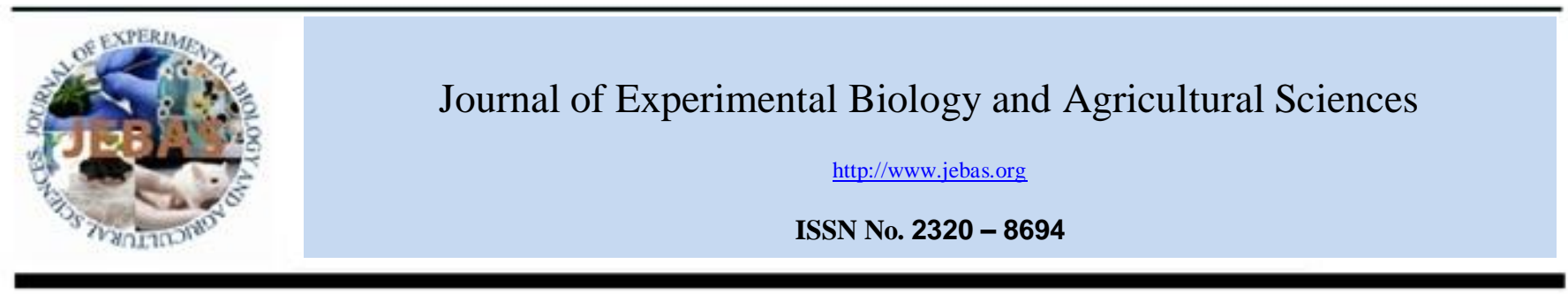

\title{
SOCIO-DEMOGRAPHIC FACTORS AND FISH EATING TRENDS IN EASTERN COMMUNITY, SRI LANKA
}

\section{Chandravathany Devadawson, ${ }^{1, *}$, Chamilla Jayasinghe ${ }^{2}$ and Ramaiah Sivakanesan ${ }^{3}$}

${ }^{1}$ Department of Zoology, Eastern University, Sri Lanka, Chenkalady 30350, Sri Lanka
${ }^{2}$ Department Food Science and Technology, Wayamba University of Sri Lanka, Makandura,Sri Lanka
${ }^{3}$ Department of Biochemistry, University of Peradeniya, Peradeniya, Sri Lanka

Received - August 19, 2015; Revision - September 02, 2015; Accepted - October 04, 2015

Available Online - October 20, 2015

DOI: http://dx.doi.org/10.18006/2015.3(5).423.429

KEYWORDS
Fish consumption
Sociodemographics
Nutrition
Appearance
Health

\begin{abstract}
Fish are considered as a unique source of protein and long chain polyunsaturated fatty acids (PUFA). In Sri Lankan population, fish consumption habits and attitudes are determined by the availability of fish and socio-demography of fish consumers. An extensive survey was carried out among fish consumers $(\mathrm{N}=1777)$ in stratified random manner. Among the total studied respondents, $73.3 \%$ of the respondents had eaten all type of fish while $10 \%$ had only sea fishes, $19.5 \%$ brackish water and rest $4.2 \%$ had eaten fresh water fishes. Furthermore, of total $19.1 \%$ people had consumed fish daily while $80.9 \%$ people had consumed fish weekly or monthly. Results of the study concluded that $64 \%$ studied respondents had fish at both lunch and dinner time while $25 \%$ had three times and rest $11 \%$ consumed only at lunch. The choice of fish in market were determined by various factors such as taste $(5.7 \%)$, smell $(8.5 \%)$, appearance $(51.5 \%)$, nutrition $(2.1 \%)$, availability (12.7\%), prize (37.3\%), health (14\%), quality (53\%), shape $(26.7 \%)$ and considered all $(24.2 \%)$. However, consumers were drawn their attention more than one factors in selecting fish from market. The results explained that quality of fish considered mostly in selection of fish with factors like prices and availability of fish. Among the studied respondents, the quantity of fish consumption varied with age such as $37.8 \%$ respondents which were belongs to the 36 45 age group had $30-40 \mathrm{~g}$, while $27.5 \%$ were between ages of $46-55$ had $41-50 \mathrm{~g}$ daily and frequency of consumption was not independent of age $(\mathrm{P}<0.001)$. Of the total respondents, the trends of fish consumption for health purpose were varied and $37 \%$ respondents consume it to cure from heart diseases, while the $23 \%$ had fish to release pressure stroke (15\%), eyesight $(13 \%)$ and during pregnancy
\end{abstract} (7\%).

* Corresponding author

E-mail: stanley@esn.ac.lk (Chandravathany Devadawson)

Peer review under responsibility of Journal of Experimental Biology and Agricultural Sciences.

Production and Hosting by Horizon Publisher (www.myvision.webs.com/horizon.html).

All rights reserved.
All the article published by (Journal of Experimental Biology and Agricultural Sciences) / CC BY-NC 4.0

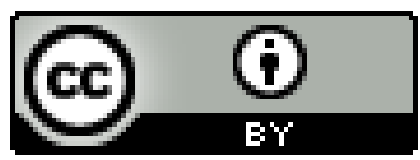




\section{Introduction}

Fish represents a unique source of long chain poly unsaturated fatty acids (PUFA) of the n-3 family mainly eicosapentaenoic acid (EPA) and docosahexaenic acid (DHA), which played an essential role in human health (Sindu, 2003). Fish is generally considered as cheapest proteinous diet for two third population of the world. It provides essential fatty acids and many other nutrients (Wang et al., 2009). The health research revealed that high consumption of fish oil (omega-3) reduced the risk of many diseases, particularly cardiovascular diseases (Trondsen et al., 2004). The raising world population, higher living standards and overall good image of fish among consumers are the possible reasons of increasing fish consumption (Verbeke et al., 2007). Myrland et al. (2000) reported that recently demand for seafood has been increased at consumer level particularly due to its benefits to health. Fish food consumption is influenced by many factors such as socioeconomic background, food consumption patterns, personal health status, attitudinal dimensions (Trondsen et al., 2004), society (Anderson \&Morris, 2000), age (Yadin, 2002), household income and education level (Olsen et al., 2007).

Previous studies regarding seafood consumption has been shown that taste, health/nutrition and convenience are important determinants of seafood consumption behavior (Olsen, 2003). Stem et al. (1997) stated that the consumption can be properly understood through the analysis of multiple factors such as economic, cultural, social, religious, marketing and personal factors. The cooking and eating practices in a population is complex due to the multiplicity of different factors which are involved in the process of choosing, acquiring, preparing and consuming food as stated by Watson et al. (2011). Eating practices is considered as an important life style determinants of health (Dynesen et al., 2003). The relationship between consumption of omega-3 fatty acids and pulse rate variability have added a new dimension to the possible cardio protective effects of omega-3 fatty acids and the high intake of fish in the early Eskimo and Japanese studies is associated with a low mortality of coronary heart disease (CHD)(Nordoy, 2001). Sri Lanka is a multi ethnic and multi religious country with long history and diverse cultural traditions. Cultural values are increasingly interwoven with fish consumption. It can be said that the consumer behavior and consumption habits regarding fish foods are important factors affecting the development of seafood sector. Therefore, attitudes and habits of consumers were studied to determine these factors in many countries (Trondsen et al., 2004; Wang et al., 2009).

Present study has been formulated to evaluate the fish consumption habits, eating practices and preferences of fish. Furthermore, an attempt was also undertaken to explore the attitudes and knowledge regarding fish food consumption which were focused with sociodemographic characteristics of fish consumers.

\section{Materials and Methods}

\subsection{Questionnaire Design and Data Collection}

The survey was conducted in 2014 for extracting information related to fish food consumption by Eastern Sri Lankan consumers. Data were collected by personal interviews in Batticaloa district of Sri Lanka which is also known by the land of singing fish where 90 percent of people consume fresh fish. The district having surface area $2854 \mathrm{Km}^{2}$ and the populations is around 586,399 and the population intensity had varied in 14 divisional secretariats division. Two trained interviewers were carried out the personal interview based on the pre-tested questioners to stratified randomly selected 1777 respondents. Appropriate sample size was determined with the help of online sample size calculator (Raosoft, 2004 available on http://www.raosoft.com/samplesize.html) which is based on the amount of error that can be tolerated, the confidence level that is desired and the population size. In this research, error rate was set to $5 \%$, confidence interval was set to $95 \%$ and population size was set to 1777 . Data was collected from 14 Divisional Secretariats, Batticaloa, Sri Lanka.

The questionnaire contained 100 questions; about 20 of them were about demographic characteristics (gender, age, income, employment, marital status, and other habits). The first question regarding fish food consumption and it was "Do you consume fish?" If the answer was "No" the reason has been asked for the same and the questionnaire was ended. The second question regarding the type of fish eating whether like or not like the type of fish and the possible reasons offered were taste-odor, smell, healthy, fleshy, fatty, quality, appearance, price, being troublesome to prepare, vegetarianism, unhealthy, bones, and other reasons. Questioner also have a section which was designed for extracting the information regarding the frequencies of fish consumption viz daily/ weekly /monthly /occasionally and times of eating.

An another section of the questioner was based on the preparation/cooking procedure of fish products i.e. with water and other spices, fish curry prepared with coconut milk and spices, fish curry prepared with fried coconut oil and with coconut milk, fish curry prepared with fried vegetable oil and with coconut milk and fried fish using different oil. To aware of processed fish food consumption, question asked "yes or no" the eating of processed fish. If the answer was "Yes"; the possibilities that eat more processed fish foods i.e. smoked, canned, brine salted, dried, and jadi were questioned. The participants were also asked if there are fish foods other than fish such as shrimps and crabs that they do / do not consume and the reasons. The factors which were focused on the choice of purchasing fish in market and how much money spent for fish purchasing was also discussed with the respondents. The subjects were also questioned regarding the average fish consumption (gram) per day by respondents. 
Table 1 The eating style and frequency of eating fish.

\begin{tabular}{|lccc|}
\hline Eating Style & Frequency & Valid Percent & Cumulative (\%) \\
\hline Fish Curry with water & 1 & 0.1 & 0.1 \\
\hline Fish Curry fried with Vegetable oil & 49 & 2.8 & 2.8 \\
\hline Fried fish & 11 & 0.6 & 3.4 \\
\hline Fish Curry with Coconut milk & 230 & 13 & 16.4 \\
\hline Fish Curry fried with Coconut oil and milk & 1486 & 83.6 & 100.0 \\
\hline Total & 1777 & 100 & 100 \\
\hline
\end{tabular}

Table 2 The purchase of fish by the consumers.

\begin{tabular}{|lccc|}
\hline Cost of Fish (SLRs)* & Frequency & $\%$ & Cumulative (1\%) \\
\hline $\mathbf{2 0 0 - 4 0 0}$ & 1539 & 87.2 & 87.2 \\
\hline $\mathbf{4 0 0 - 6 0 0}$ & 194 & 11.0 & 98.2 \\
\hline $\mathbf{6 0 0 - 8 0 0}$ & 18 & 1.1 & 99.3 \\
\hline $\mathbf{8 0 0 - 1 0 0 0}$ & 13 & 0.7 & 100.0 \\
\hline Total & 1764 & 100.0 & 100.0 \\
\hline
\end{tabular}

Sri Lankan Rupees (1US\$= 130SLRS)

Table 3 The frequency of eating fresh fish by people

\begin{tabular}{|lccc|}
\hline Value & Frequency & Percentage (\%) & Cumulative (\%) \\
\hline \multicolumn{1}{|c|}{$(\mathbf{N})$} & 339 & 19.1 & 19.1 \\
\hline 3days/week & 1437 & 80.9 & 100.0 \\
\hline 2days/week & 1063 & 74.0 & 74.0 \\
\hline 3days/month & 67 & 4.7 & 78.6 \\
\hline 2days/month & 10 & 0.7 & 79.3 \\
\hline 1day/month & 2 & 0.1 & 79.5 \\
\hline 1day/week & 2 & 0.1 & 79.6 \\
\hline 6 days/week & 29 & 2 & 81.6 \\
\hline 4days/week & 254 & 17.7 & 99.3 \\
\hline 5days/week & 4 & 0.3 & 99.6 \\
\hline
\end{tabular}

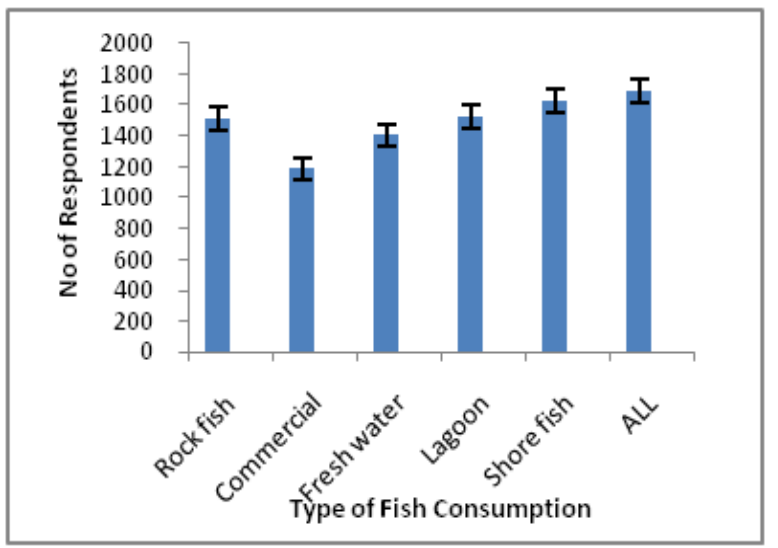

Figure 1 The number of respondents consumed the different type fish. Data represented as total number of respondents who responded the type of fish. $99.4 \%$ of respondents consume all type of fish.

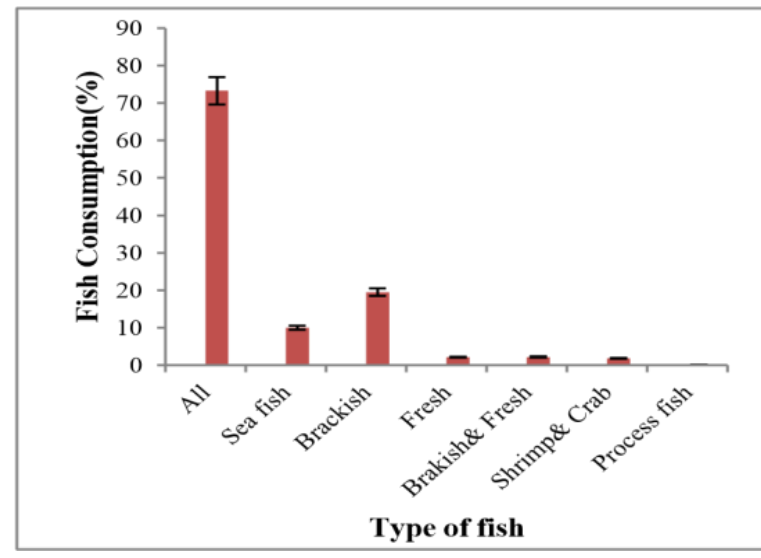

Figure 2 The percentage of respondents who consume type of fish stated by the respondents, Data represented as percentage (\%) of the respondents of the total respondents (1777). Here significantly high respondents eat all type of fish $(\mathrm{P}>0.01)$. 


\subsection{Data Analysis}

A pre- tested semi structured questionnaires were applied to 2000 respondents, 223 of them were eliminated because of unreliable responses. Therefore 1777 questionnaires were evaluated to obtain results. The answers were transferred to Microsoft Excel Office Program 2007 version. After a review the data were process and analyzed by IBM SPSS 10 statistical software. Frequency tables, cross tabulation and contingency table, modules of the software were run in order to get statistical results. Cross tabulation was often used to show and analyze the relation between two or more categorical variables. It gives the frequency distribution of the variables in a matrix format. Factors influencing the purchasing behavior were analyzed using Kruskal - Wallis Test.

\section{Results and Discussion}

\subsection{Consumers Preference}

Preference of fish consumption varied among the consumers (Figure 1), the trends of fish preference observed in this study are rockfish (88.8\%), commercial fish $(69.7 \%)$, freshwater fish $(82.6 \%)$, lagoon fish $(89.8 \%)$ shore fish $(95.6 \%)$ and all type (99.4\%). Result of study revealed that $73.3 \%$ of the studied respondents consumed at least one type of fish, while $10 \%$ consumed only sea fishes, $19.5 \%$ consumed brackish water fishes and $4.2 \%$ people ate only freshwater fishes (Figure 2 ).

Like choice, the time of consumption also showed huge variation among the studied respondents. Amongst the total studied respondents (1777), $19.1 \%$ people had the fish daily whereas $80.9 \%$ people had fish either weekly or monthly. Of them $64 \%$ of people had fish two times (at lunch \&dinner) whereas $25 \%$ people had three times and $11 \%$ had fish during lunch time only (Figure 4).

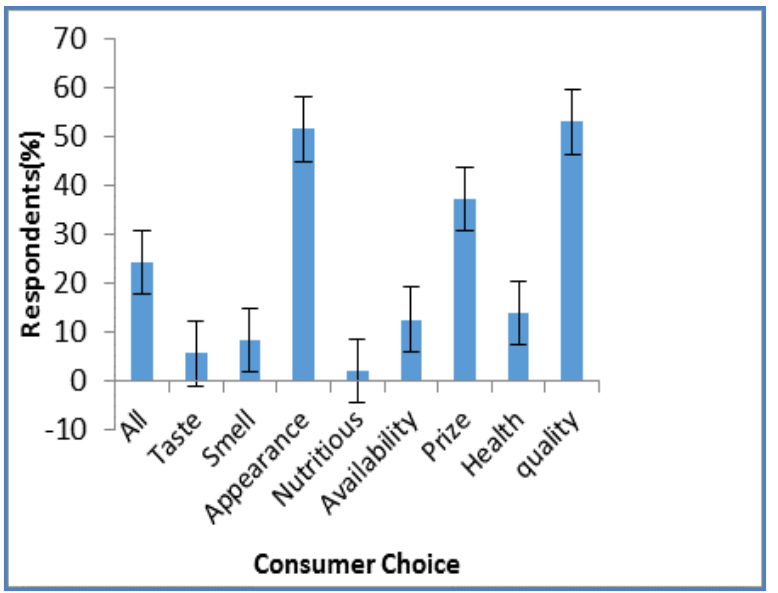

Figure 3 The number of respondents (\%) show the choice of fish during purchasing in market. Data represented as number of respondents in \%.
The priority in purchasing fish from market was a complex process and determined by many factors (Figure 3) such as taste $(5.7 \%)$, smell $(8.5 \%)$, appearance $(51.5 \%)$, nutrition $(2.1 \%)$, availability $(12.7 \%)$, price $(37.3 \%)$, health $(14 \%)$, quality (53\%), shape (26.7\%) and considered all (24.2\%). Quality and appearance are the factors which mostly considered by all the consumers, however, most of the consumers draw their attention in one or more factors during the purchasing of fish. The consumers stated certain kind of fishes like most, the rock fish (87\%), commercial fish (70.6\%), fresh water fish( $82.7 \%$ ), lagoon fish $(89.5 \%$ ) and shore fish $(95.6 \%)$ and not like the rock fish $(6.8 \%)$,commercial fish $(24.4 \%)$, fresh water fish(13.1\%), lagoon fish $(7.1 \%)$, and shore fishes $(0.1 \%)$ due to their quality and appearance (Figure 2).

Kreider et al. (1993) reported that consumers preferred fish and fish food that do not have a "fishy" taste or odor. However, dislike of fish and other sea foods could be depending on many other factors (Leek et al., 2000). Appearance of fish was always an important indicator in fish selection in this study although taste-preferences towards fish food were known as the most important predictors of seafood consumption behavior (Olsen, 2003). This findings was supported the hypothesis that the factors such as freshness, good appearance, flavor, safety and price were all ahead of nutrition in importance. Kreider et al. (1993) stated that all other factors were important before the price.

According to Hicks et al. (2008) reported that the consumers believed that sea fish were too expensive. However, Xiang-guo (2002) mentioned that price was not considered as an important factor affecting fishery products purchasing decisions of consumers as compared with quality. It was also stated that none of the participants, who did not consume seafood, considered them as unhealthy.

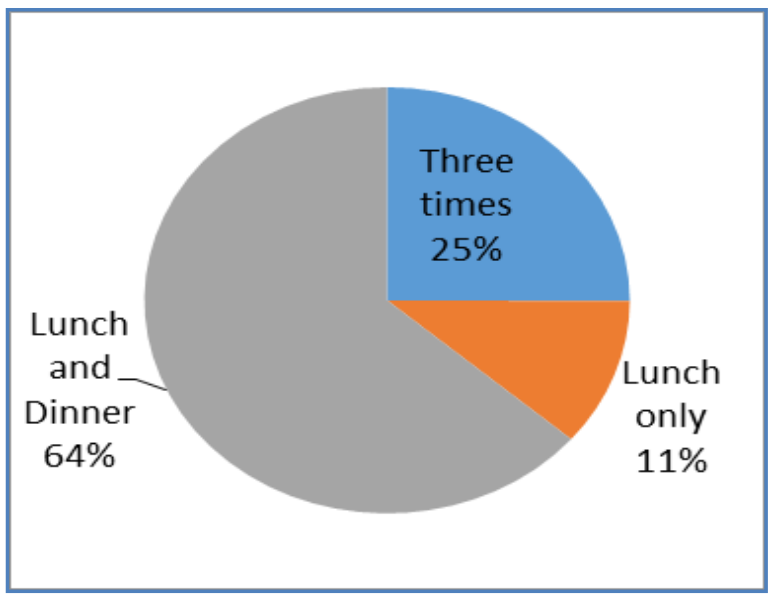

Figure 4 The fish eating trend among studied respondents in percentage. 


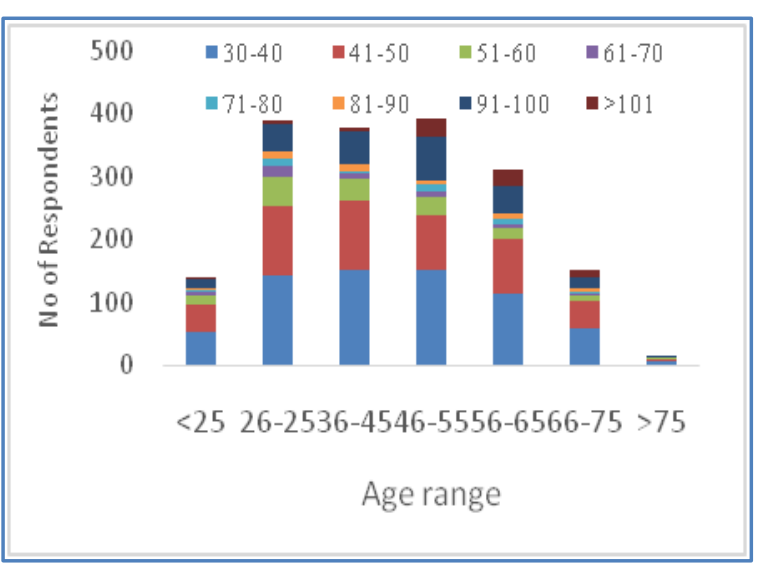

Figure 5 The amount fish eating (in gram) is correlated with the age of respondents. Age between 25 - 45 showed lowest fish consuming rate.

\subsection{Consumers Frequency and eating style}

The total of 1777 respondents, $19.1 \%$ people had fish daily while $80.9 \%$ of people had fish weekly. Among these studied respondents a small groups of respondents (17.7\%) had fishes six times/ week while the majority of the respondents $(74 \%)$ had only three times in a week (Table 3). The amount of fish consumption varied among consumers and the trends of this are as follows $37.8 \%$ of people had about $30-40 \mathrm{~g}$ fish or fish products in a day while $27.5 \%$ respondents had $41-50 \mathrm{~g}$ and rest $13.9 \%$ had 91-100g fish daily or weekly (Figure 5). According to Hicks et al. (2008) $46 \%$ of current seafood eaters from US consumed sea foods once or more times in a week while $29 \%$ of them consumed limited times per month and rest $25 \%$ were consumed fish or fish products in a month or less. In this study, frequency of fish eating is correlated with the demographics of the respondents as $53.6 \%$ of respondents are poor income people and for them fish availability is rare and because of this they consumed less fish or fish products. In Flanders, survey participants consumed fish on average, 4.6 times per month, and $61.7 \%$ of them had fish at least once a week (Verbeke et al., 2007). The choice of fish and its consumption was correlated with sociodemographic characteristics of the consumer.

The eating style of fish among consumers varied and of the total respondents, $83.6 \%$ eat fish by cooking in coconut milk fried with coconut oil, $13 \%$ eat fish curry made with coconut milk without oil, $2.8 \%$ fish curry made fried fish in vegetable oil and $0.6 \%$ eats only fried fish (Table 1). It was also reported that traditionally, the people are very experienced to cook fish curry with coconut milk which is very tasty and popular in Sri Lankan dishes. Kabahenda et al. (2012) stated that at the household level, how food is handled, prepared and cooked influence the nutritional value of what is consumed. However, types of ingredients and the amount of the coconut milk and spices that are added in cooking fish curry are varied among the respondents though a common procedure was adopted to

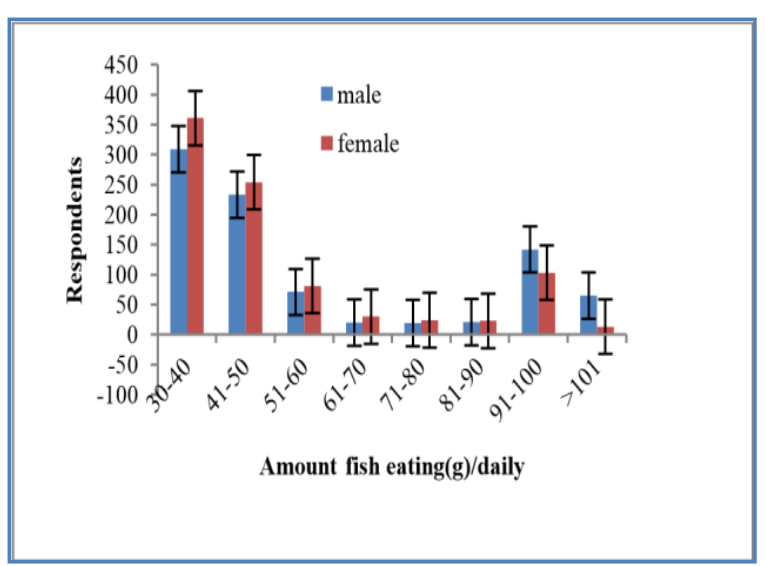

Figure 6 The amount of fish (g) eating among the respondents male $(49.7 \%)$ and female $(50.3 \%)$.

prepare fish curry with coconut milk. Due to variation of recipe of making fish curry, the nutrient value can be varied (Table 1). The purchasing of fish in market was controlled by the consumer's behavior and demographics characteristics. Among the total studied respondents, $87.2 \%$ of consumers bought fish for 200-400 SLRs (3.5US\$) and they bought seashore and lagoon fishes while only $0.7 \%$ of people bought above 800-1000 SLRs (10 US\$) and selected rock and commercial fishes (Table 2). It was reflected that the socioeconomics played an important role in the selection fish in Sri Lanka. A remarkable percentage $(66.02 \%)$ of seafood consumers believed that sea foods took less place in their diet than that of it should be. During this survey, $44.10 \%$ of them stated that the place of sea foods in their diet will increase if sea foods became easily available. The other possible ways to increase consumption were lowering the price $(39.30 \%)$ and preparing fish as ready to cook $(25.09 \%)$.

Some of the participants $(7.20 \%)$ stated that they did not eat more fish foods since they did not like too much according to present interview (Figure 3). In Norway, lack of fresh fish supply and variation in quality were pronounced as important reasons for not eating more fish by $69 \%$ of those who thought that they did not consume enough fish. The other reasons of the respondents, who felt that they did not eat enough fish were 'family did not like fish', 'there were very few product choices', 'they did not like the taste of fish', and 'prices were too high' (Trondsen et al., 2004). In present study $13.9 \%$ of the surveyed consumers stated the choice of fresh fish based on the good quality (Figure 3). Factors that influenced decisions of purchasing fish varied according the respondents demographics. The sociodemographic factors are most influential towards eating practices, among these gender, age, socio-economic status represented by education and occupation were the most important one (Krieg et al., 2012). Wheeler (1991) stated that quantities of fish distributed among family members depend on cultural and power determined norms with respect to sex and age. 


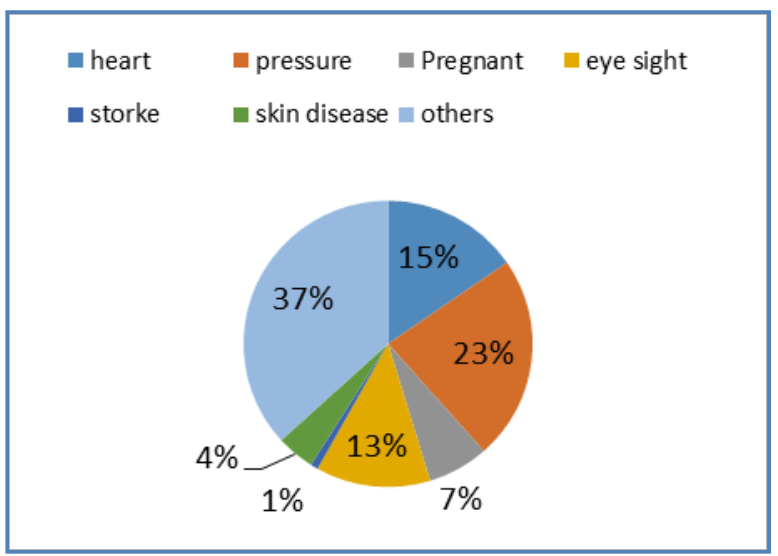

Figure 7 The choice of fish based on the health. Here The percentage of respondents for selecting fish for different health.

\subsection{Sociodemographics}

Demographic characteristics of the respondents were directly correlated with fish consumption. In present study, $50.3 \%$ females and $49.7 \%$ males between ages of 25 - 75 were responded (Figure 6). Results of study revealed that the age was significantly correlated at 0.001 level $(\mathrm{P}=0.001)$ with the amount of fish eating and the Pearson correlative coefficient (0.073). As a result of questionnaire, $33 \%$ of the respondents had fish daily between the ages of 36-45 as rate of $30-40 \mathrm{~g}$, whereas a $15 \%$ of respondents had fish daily between 91 $100 \mathrm{~g}$ at age between $56-65$. The fish consumption rate was $30-$ $40 \mathrm{~g}$ between the Middle ages i.e. 36-55years (Figure5). Reasons of fee consumption varied with consumers, among the total studied respondents (Figure7), 37\% respondents were consumed it to cure from heart diseases, while the $23 \%$ had fish to release pressure stroke (15\%), eyesight (13\%) and during pregnancy $(7 \%)$.

This study was not any correlation between the fish consumption increase age despite some study stated that increase in fish food consumption directly depending on the age. Beside the independence test results had that consumption frequency was not independent of age $(\mathrm{P}>0.001)$.

The amount of fish consumption was significantly correlated with the sex of consumers at 0.01 level $(2$-tailed $)(\mathrm{P}=0.001)$. The highest percentage of male and female had the fish 30-40 $\mathrm{g} /$ daily as it was stated that the desired fish were more expensive in the market. A $23 \%$ low income people (less than 10,000 SLRs) had fish at a rate of $30-40 \mathrm{~g}$ daily whereas $16 \%$ of consumed fish at a rate $41-50 \mathrm{~g}$ as stated by the respondents (Figure 2).

\section{Conclusion}

In conclusion, fish consumption was determined by many factors, among them, sociodemographics factors played major role in choosing fish and decision of eating of fish among the studied community.

\section{Acknowledgement}

The author would like to thank Eastern University, Sri Lanka for granting University Research Grant to undertake the study for the period of 1 year.

\section{Conflict of Interest}

The authors whose names are listed above that they have no affiliations with or involvement in any organization or entity with any financial interest or non-financial interest in the subject matter or materials discussed in this manuscripts.

\section{References}

Anderson AS, Morris SE (2000) Changing Fortunes: Changing Food Choices. Nutrition \& Food Science 30: 1215.http://dx.doi.org/10.1108/00346650010304701.

Dynesen AW, Haraldsdottir J, Holm L, Astrup A(2003) Sociodemographic differences in dietary habits described by food frequency questionsresults from Denmark. European Journal of Clinical Nutrition 57: 1586-1597. doi:10.1038/sj.ejn.1601728.

Hicks D, Pivarnik L, McDermott R (2008) Consumer perceptions about seafood-an Internet survey. Journal of Food Service, 19: 213-226. doi:10.1111/j.1748-0159.2008.00107.x

Kabahenda MK, Amega R, Okalany E, Husken SMC, Heck S (2012) Protein and micronutrient composition of low-value fish products commonly marketed in the Lake Victoria region, World Journal of Agricltural Sciences 7: 521-526.

Kreider CR, Gempesaw CM, Bacon JR, Toensmeyer UC, Groff AJ (1993) An Analysis of Consumer Perceptions of 
Fresh Fish and Seafood in the Delmarva Region. Journal of Food Distribution Research 4: 37-48.

Krige S, Mahomoodally F, Subratty A,Ramasawmy D (2012) Relationship between Socio-Demographic Factors and Eating Practices in a Multicultural Society. Food and Nutrition Sciences 3 : 286-295. doi: 10.4236/fns.2012.33042.

Leek S, Maddock S, Foxall G (2000) Situational determinants of fish consumption. British Food Journal102:18 39.http://dx.doi.org/10.1108/00070700010310614.

Myrland O, Trondsen T, Johnston RS, Lund E (2000) Determinants of seafood consumption in Norway: lifestyle, revealed preferences, and barriers to consumption. Food Quality and Preference 11:169-188. doi:10.1016/S09503293(99)00034-8

Nordoy A (2001) Fish consumption and Cardiovascular diseases. European Heart Journal - Supplements 3( Supplement D):D4-D7.

Olsen SO (2003) Understanding the relationship between age and seafood consumption the mediating role of attitude, health involvement and convenience. Food Quality and Preference 14: 199-209.doi:10.1016/S0950-3293(02)00055-1

Olsen SO, Scholderer J, Brunsø K, Verbeke W (2007) Exploring the relationship between convenience and fish consumption: a cross-cultural study. Appetite 49: 84-91. doi:10.1016/j.appet.2006.12.002.

Raosoft (2004) Sample size calculator on http://www.raosoft.com/samplesize.html access on $25^{\text {th }}$ May, 2015.

Sindu KS (2003) Health benefits and potential risks related in consumption of fish or fish oil.Regulatory Toxicology and Pharmacology 38:336-344.doi:10.1016/j.yrtph.2003.07.002.
Stem PC, Dietz T, Ruttan VW, Scoclov RH, Sweeney JL (1997) Consumption as a problem for environmentalscience. Environmentally Significant Consumption: Research Directions, Washington, DC: National Academy Press Pp. 111.

Trondsen T, Braaten T, Lund E, Eggen AE (2004) Health and seafood consumption patterns among women aged 45-69 years. A

Norwegian seafood consumption study. Food Quality and Preference 15: 117-128.doi:10.1016/S0950-3293 (03)00038-7

Verbeke W, Vanhonacker F, Sioen I Camp JV, De Henauw S ( 2007) Perceived Importance of Sustainability and Ethics Related to Fish: A Consumer Behavior Perspective. AMBIO: A Journal of the Human Environment 36:580-585..doi: http://dx.doi.org/10.1579/0044-7447(2007)36[580:PIOSAE]2.0.CO;2

Wang F, Zhang J, Mu W, Fu Z, Zhang X (2009) Consumers' perception toward quality and safety of fishery products, Beijing, China. Food Control 20: 918-922. doi:10.1016/j.foodcont.2009.01.008

Watson RR, Gerald JK, Preedy VR(2011) Nutrients, Dietary Supplements, and Nutriceuticals: Cost Analysis Versus Clinical Benefits. Humana Press, c/o Springer ScienceBusiness Media, LLC, 233 Spring Street, New York, NY.

Wheeler EF (1991) Intra-household food and nutrient allocation. Nutrition Research Reviews 4: 69-81.

Xiang-guo Z(2002) Consumption trends and habits for fishery products in China, ASEM Aqua challenge workshop Available at: http://www.imbc.gr/biblio_serv/aquachallenge /xiang.html. access on $25^{\text {th }}$ May, 2015 .

Yadin DL (2002) “ The International Dictionary of Marketing : Over 2000 Professional terms and Techniques", Kogan Page Publishers, London. 